See Article page 193.

\section{Commentary: Searching for liquid gold}

\author{
Hellmuth R. Muller Moran, MD, ${ }^{\mathrm{a}, \mathrm{b}}$ and \\ Rakesh C. Arora, MD, PhD, FRCSC ${ }^{\mathrm{a}, \mathrm{b}}$
}

Like prospectors scouring the reaches of the American frontier, many physicians regularly conduct their own kind of prospecting in the intensive care unit (ICU), seeking to optimize postoperative urine output in their patients after cardiac surgery. The association between renal dysfunction and adverse outcomes has been demonstrated numerous times-in cardiac surgery patients ${ }^{1}$ and others ${ }^{2}$ - but the decision for and timing of intervention are less clear. In their Expert Review, Merritt-Genore and colleagues ${ }^{3}$ attempt to provide insight into this important question by examining the evidence for early and late initiation of renal replacement therapy (RRT) for acute renal injury or failure after cardiac surgery.

The authors highlight a number of important issues related to RRT in cardiac surgery patients. Large studies and meta-analyses from the ICU literature have suggested that the timing of RRT does not affect outcomes, yet this conflicts with data derived from cardiac surgery patients. Early RRT seems to promote the maintenance of euvolemia with a consequently shorter ICU length of stay, although not consistently. Finally, in the cardiac surgery literature there is evidence to suggest that patients with advanced conditions such as right ventricular failure, recent heart transplantation, shock, or the need for mechanical circulatory support, may react differently to RRT than their counterparts, which certainly is biologically plausible.

From the a Division of Cardiac Surgery, Department of Surgery, Max Rady College of Medicine, University of Manitoba, Winnipeg, Manitoba, Canada; and ${ }^{\mathrm{b}}$ Cardiac Sciences Program, St. Boniface Hospital, Winnipeg, Manitoba, Canada.

Disclosures: Dr Arora reported an unrestricted grant from Pfizer Canada Inc and honoraria from Abbott Nutrition, Edwards Lifesciences, and AVIR Pharmaceuticals for work unrelated to this manuscript. Dr Muller Moran has reported no conflicts of interest.

The Journal policy requires editors and reviewers to disclose conflicts of interest and to decline handling or reviewing manuscripts for which they may have a conflict of interest. The editors and reviewers of this article have no conflicts of interest.

Received for publication March 22, 2021; revisions received March 22, 2021; accepted for publication March 24, 2021; available ahead of print April 28, 2021.

Address for reprints: Rakesh C. Arora, MD, PhD, FRCSC, I.H. Asper Clinical Research Institute, CR3015, 369 Tache Ave, Winnipeg, Manitoba, Canada R2H 2A6 (E-mail: rakeshcarora@gmail.com).

JTCVS Open 2021;6:198-9

2666-2736

Copyright (C) 2021 The Author(s). Published by Elsevier Inc. on behalf of The American Association for Thoracic Surgery. This is an open access article under the CC BY-NC-ND license (http://creativecommons.org/licenses/by-nc-nd/4.0/).

https://doi.org/10.1016/j.xjon.2021.03.017
Check for updates

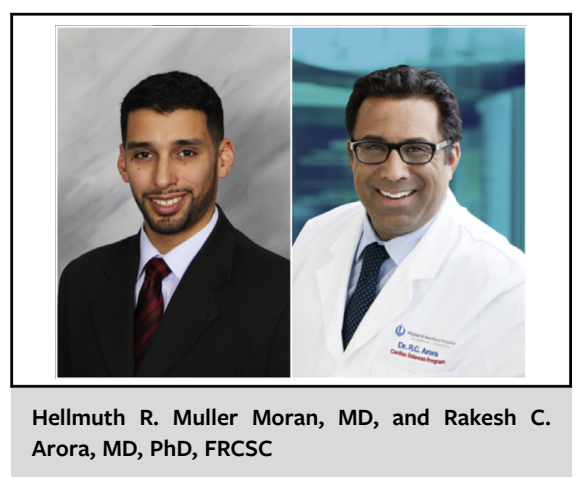

CENTRAL MESSAGE

The optimal timing of renal

replacement therapy after car-

diac surgery is unclear, but avail-

able perioperative care

recommendations may still

reduce the burden of postoper-

ative renal injury.

This review is limited by the heterogeneity of included studies, particularly with regard to their design, population, endpoints, and even definition of what constitutes early and late RRT. Much of the available data is derived from the general ICU population and not from cardiac surgery patients. As the authors rightly state and as is corroborated by the observed differences in data signals, enough factors exist to call into question whether cardiac surgery patients are sufficiently similar to the general ICU population for these results to be applicable. It can be argued that they are not.

Nonetheless, although we agree wholeheartedly with the authors' recommendations designed to generate highquality data that are directly applicable to cardiac surgery patients, there are still opportunities to translate available evidence to the bedside. It is clear that acute kidney dysfunction is harmful and that the consequences are worse with increasing severity. ${ }^{1,2}$ Once a patient's renal function has deteriorated to the point when RRT is being considered, the opportunity for risk reduction of serious perioperative morbidity has likely passed. Thus, strategies to identify such patients early and to preemptively curb the progression of perioperative kidney injury are likely to pay dividends. With this in mind, the Enhanced Recovery After Cardiac Surgery Society recommends the use of urinary biomarkers to identify at-risk patients and goal-directed fluid therapy to guide perioperative resuscitation. ${ }^{4}$ Until such time as more definitive data are available to guide the timing of RRT in 
cardiac surgery patients, the consistent implementation of such recommendations may be a useful process measure for units seeking to reduce the impact of postoperative renal-related morbidity and mortality.

\section{References}

1. Hu J, Chen R, Liu S, Yu X, Zou J, Ding X. Global incidence and outcomes of adult patients with acute kidney injury after cardiac surgery: a systematic review and meta-analysis. J Cardiothorac Vasc Anesth. 2016;30: $82-9$.

2. Hoste EAJ, Kellum JA, Selby NM, Zarbock A, Palevsky PM, Bagshaw SM, et al Global epidemiology and outcomes of acute kidney injury. Nat Rev Nephrol.2018; $14: 607-25$.

3. Merritt-Genore H, Sarber KM, Thompson S. Accelerated versus delayed initiation of renal-replacement strategies following cardiac surgery. J Thorac Cardiovasc Surg Open. 2021;6:193-7.

4. Engelman DT, Ben Ali W, Williams JB, Perrault LP, Reddy VS, Arora RC, et al Guidelines for perioperative care in cardiac surgery: enhanced recovery after surgery society recommendations. JAMA Surg. 2019;154:755-66. 